\title{
8. Is that a human skull? All in the name of art!
}

\section{Dianne McGowan}

This chapter explores the ambiguities of Western beliefs in relation to the sacredness of the Western human body, especially in death. These ambiguities are highlighted by considering the contemporary transformation of Tibetan Buddhist ritual objects into Western art objects. Having the cross-cultural and historical specificity of concepts of and treatment of the body as sacred in death the chapter explores the de-sacralisation of the dead body in contemporary European culture, especially in the art of Gunther von Hagans.

The chapter is divided into three parts: the first introduces Tibetan Buddhist customs and objects; the second describes the historical European attitudes to human bone; and the third muses over the acceptance of Tibetan Buddhist human bone objects as art and Western notions towards the sacredness of the dead.

\section{Tibetan Buddhist practices}

Anyone who has glanced at Tibetan Buddhist thangkas (Tibetan paintings) or sculpture will have noticed a vanguard of ferocious multi-armed, multi-legged and multi-headed deities, very different from that of the compassionate and peaceful seated image of Sakyamuni Buddha. For example, Yamantaka, the defeater of Yama, 'The Lord of Death', has a corpulent human body with a buffalo head, on top of which are arranged multiple human heads. His 36 flailing arms hold weapons and symbols, while his eighteen legs trample animal and human bodies underfoot. The most visible ritual human bone object held by these ferocious deities and used in ritual practice by Tibetan Buddhists is the skull-cup, which has many levels of meaning depending on what it is filled with, who holds it, and the position in which it is held. ${ }^{l}$

For example, Naro Dakini may be displayed in a thangka as a manifestation of Vajravarahi. Vajravarahi is the consort of Chakramsavara, a deity around which the current Dalai Lama holds many initiation ceremonies. Naro Dakini is portrayed as pouring blood from a skull-cup into her mouth, the blood trickles from her mouth and her vagina, symbolising how she is both consuming, and is being consumed, by the feminine principle, wisdom. In the crook of her left arm sits a tantric staff. On the apex of this staff, above a half crossed thunderbolt and a vase of nectar, is impaled a fresh head, a decaying head, a skull and a thunderbolt. When held by a female, the whole staff represents the masculine principle, compassion. $^{2}$ Like all Tibetan symbolism, the imagery represents multiple levels and layers of meanings, such as the representation of the physical 
universe or an esoteric formula. Thangkas, like sculptures, serve as picture maps detailing how one can achieve enlightenment in just one lifetime.

Because the practice of Tibetan Buddhism ${ }^{3}$ has the potential for enlightenment in one lifetime, it is therefore, desirable to have the most potent implements with which to overcome the obstacles that trap the human in the ever-turning wheel of rebirth; that is, trapped in samsara. ${ }^{4}$ Consequently, there are religiously sanctioned lists citing the most powerful source to the least for each ritual human bone object. ${ }^{5}$ In the Naro Dakini example, an ideal skull-cup would be from a violently murdered or executed individual or an illegitimate child, aged seven or eight years, who was born from an incestuous union. The least desirable skull is from someone who died of natural old age. ${ }^{6}$ The skulls of a venerable lama or pious laymen were often embellished and furnished with a decorative tripod and cover and then placed on an altar as the vessel for the 'inner offerings' of animals and humans. ${ }^{7}$

Mortuary customs in Tibet varied according to epoch, resources, region, rank or cause of death. According to Keith Dowman, historical sources mention practices such as the mummification or cremation of high lamas and that epidemic victims were either buried or cast into the river. ${ }^{8}$ The novel Tibetan Buddhist mortuary practice, known in English as sky burial or vulture disposal, ${ }^{9}$ has been suggested as a response to the frozen landscape and the scarcity of wood, although high lamas continued to be cremated. ${ }^{10}$ Robert Ekvall suggests that the transition to sky burials by Tibetans was brought about when Buddhism was introduced in the late 700s. ${ }^{11}$ The introduction of the Buddhist doctrinal ban on killing any sentient beings, be it buffalo or bug, posed a dilemma for Tibetans. Put simply, they lived in a harsh environment where survival depended on them killing animals for clothing and food. Ekvall notes that if a Muslim butcher could not be employed, the animal was asphyxiated and the refrain, 'Oh, it is dead', was uttered before a drop of blood was shed. In the act of surviving, Tibetans accumulated de-merits against their desired release from the samsara. By voluntarily and generously giving up their own human body at death to other sentient beings, such as vultures and dogs, they acknowledge this debt. Further, the relatives watching the dismembering were reminded of the Buddhist principles, that body and life is impermanent. ${ }^{12}$

The general custom of a sky burial is that, after death the body is propped up in a seated position. A monk is employed to chant to the newly released spirit, instructing it on correct behaviour and how to make a successful journey through the transitional state of the Bardo to the next rebirth cycle. ${ }^{13}$ The ritual chant normally takes three days. Once finished, the body is tied into a foetal position and carried on a relative's back to the nearest charnel grounds. Here, the head is shaved and then the butchers begin. They open up the body, take out the internal organs, disarticulate the limbs and cut the flesh into small pieces. The 
bones are pounded into powder and mixed with water to make tsampa-like balls. ${ }^{14}$ Once finished, the vultures are summoned to accept the offering, while dogs and other small carnivorous animals clean up. ${ }^{15}$ The cremated remains of high lamas were often pounded into fine ash, mixed with medicinal substances and then added to clay, which was then used to make small votive plaques for personal shrines. ${ }^{16}$

\section{Historical European practices}

This second section focuses on the prevailing historical European attitudes involving human bone. ${ }^{17}$ It is well known that the trafficking of human bones in the name of Christianity was central to the economy of the Roman Catholic Church. Within a hundred years of Jesus' crucifixion, the bones of tortured devout followers were being recovered and handled as spiritual treasures. ${ }^{18}$ The current Catholic Church continues to officially sanction the worshipping of relics and their associated miracles. In 1974, Pope John Paul II visited Edinburgh and presented to St Mary's cathedral the shoulder blade of St Andrew, the patron saint of Scotland. ${ }^{19}$

Whether it was the acts of martyrdom or transference of pagan beliefs, the bones of the saints were believed to be pregnant with 'heavenly' powers capable of performing miracles, and the subsequent miraculous happenings fulfilled these expectations. Peter Brown suggests that relics were potent because these 'immortalised' remains or personal belongings represented the locus in which earth and heaven had met. ${ }^{20}$ Throughout Europe human bones were dug up, cut up, exhibited, toured, pillaged, stolen, and faked. The ownership of such treasures brought status and, more importantly, profit. $^{21}$ Chaucer's fourteenth century Canterbury Tales provides an insight into the business of pilgrimage. In his tale, 29 pilgrims are thrown together by their desire to visit the relics of Thomas à Becket. They were not to be disappointed. Canterbury Cathedral had glorified four sites to St Thomas, each exhibiting a bit of him. ${ }^{22}$

The cutting up of a relic to create fragments was common; the fact that Becket's body was in one location was unusual. A French researcher investigating old church inventories found that St Mary Magdalene must have had six bodies to accommodate all the relics purported to be of her. ${ }^{23}$ Because the dispersion of 'bits of true' relics could not fill the demand, secondary relics, such as the clothes martyrs and saints had worn or implements used in their torture, were also venerated. The production of fakes and stealing were other ways of acquiring a relic, the possession of which bring renown and monetary rewards to a religious organisation. The transfer of St Foy's bones from the monastery at Figéac to the Conques monastery is an example of the importance of relics and the extraordinary means some would go to acquiring a relic. Historical legend relates that, in the 900s, a Conques monk spent ten years of undercover work as a Figéac 
monk until he was entrusted as a guardian of St Foy's bones, which he then stole, taking them to the Conques monastery and bringing a renewed vigour to the community. 24

However, trafficking of human bones was not just a religious phenomenon. From the mid 1700s to 1832, the British medical profession was involved in wholesale 'body snatching'. It was estimated that, in the early 1800s, London anatomy schools were illegally procuring almost 800 bodies a year. London was also supplying Oxford and Edinburgh. ${ }^{25}$ There was opposition to the nightly activities of these 'resurrection men', as they became known, especially if they dug up a body belonging to the upper classes. Nevertheless, others approved the 'getting' of bodies in the name of science. However, intentional murder for anatomy subjects finally forced the Anatomy Act of 1832 to be passed. ${ }^{26}$

The most common established mortuary practice in Europe was interment. ${ }^{27}$ By the 1600s, burial meant buying a plot of land within an area designated for the disposal of bodies. In seventeenth century Britain, only royalty and priests were buried in clothes, the rest were wrapped in a shroud, and only the wealthy could afford a coffin. ${ }^{28}$ The county council buried paupers as best befitted the pauper's beliefs, if known. By the 1700s, Vanessa Harding notes the great fear of dying as a pauper. Not being able to afford a proper burial was a social disgrace. The adherence to restrictive mourning customs identified and reinforced the family's social identity and standing within the community. ${ }^{29}$ Nigel Llewellyn notes that all funeral paraphernalia had only one function, '...they were designed to display and reinforce the social distinctions of the dead'. He also notes that the mourning paraphernalia not only displayed social rank, it also created visually recognised public and private spaces in which particular outpourings of grief were acceptable. ${ }^{30}$

\section{Musings}

Having presented a general outline of the cultural practices of both Tibetan Buddhism and the West, this last section of the paper ventures to integrate this information into contemporary Western practices and ponder on the observable ambiguities. To start these musings I turn to museum exhibitions of Tibetan ritual objects including human remains, and how researchers approach and handle such material. There is no public outcry of sacrilege over a museum exhibition of human remains, or of how researchers, such as me, may handle them. ${ }^{31}$ Why? If the skull were Thomas à Becket's or a close relative of mine, would I be treating their skull with the same apparent detachment I appear to be displaying to the Tibetan material? Perhaps the elevation and desire of Tibetan human bone objects as art objects ameliorates thoughts of sacrilege? Or perhaps time, cross-cultural circumstances or no personal attachment to the skeletal remains dampens the emotional input? Does 'political correctness' govern moral 
outrage? After all, the Tibetans carry no corresponding outrage. While I do not have answers to these questions, or the many others I could have asked, I will venture to appraise these questions in reference to the Tibetan example.

What attitude does the West have towards Tibet? Historically, Tibet has been an anomaly, Tibetans were not seen as 'noble savages' nor were they seen as cannibals, even though their religious imagery was full of partial corpses and skeletons, not to mention the human bone objects that would have been on the altar or seen in ritual dance. ${ }^{32}$ Rather, the apparent worship of human bone paralleled the Catholic veneration of relics and the construction of reliquaries. Many early observers of Tibetan practices noted parallels with Catholicism, especially similarities in dress, ritual, ecclesiastical furnishing and the privileging of text. In 1661, the first European to reach and report on Lhasa, Father John Grueber, a Jesuit missionary, noted the strong similarities between Tibetan ritual and Catholicism. He suggested that Tibetan Buddhism must have begun as an early type of Christianity and that its development had since been corrupted by the Devil. He wrote that the Devil 'hath had the malice to transfer and usurp all the other mysteries of our faith to his own worship'. ${ }^{33}$ Earlier, Marco Polo had suggested the work of the Devil. In the 1200s, he observed Tibetans at the Great Khan's court and he wrote that they were wise astrologers and great enchanters, who could change the weather at will. But they did this because they were in league with the Devil. The 1959 Polo translation reads, '[t]hey know more of diabolic arts and enchantments than any other men. They do what they do by the art of the Devil; but they make others believe that they do it with great holiness and by the work of God.' 34

This ambiguous perception of the Tibetans as being either in the service of the Devil or their God, or of being either holy or enchanters, has continued, with many myths accepted into popular Western culture. For example, in 1930, the New York Times ran an article on an exhibition opening at the Field Museum of Natural History in Chicago, titled 'Made from Human Bones'. ${ }^{35}$ What is interesting is that this article repeats a story first made popular in 1366, by John Mandeville: the practice of the Tibetan son drinking from his father's skull-cup in ancestor worship. ${ }^{36}$

While scholars and the increasing numbers of Westerners practising Tibetan Buddhism are discrediting these recurring popular myths, there is another re-contextualisation of Tibetan Buddhism apparent today. The labelling and cataloguing of Tibet's culture as art is effectively re-writing Tibetan Buddhist ritual objects as pieces to be valued for their colour, form, rarity and uniqueness; in short, for their aesthetic value. In 2003, there were three Tibetan 'art blockbuster' exhibitions circulating in the United States. ${ }^{37}$ Each drew enthusiastic crowds wherever they went and each had a different agenda in their promotion of Tibetan art. All three exhibitions acknowledged that the 
objects were selected according to Western art aesthetics. The enthusiastic and generally uninitiated audience is given a de-contextualised version of Tibetan culture.

For example, an extract taken from a catalogue entry for Naro Dakini in the exhibition titled 'Desire and Devotion: Art from India, Nepal, and Tibet,' reads:

In this rather loosely painted thangka, Naro Dakini stands on a lotus in the militant pose (pratyālidha), trampling two personifications of obstacles. Of red complexion, she is naked except for her ornaments and garland of severed heads. While holding a chopper with her right hand, she tilts the skull cup with the left to drink the blood. Her magic staff rests horizontally across her shoulder. Surrounded by an oval, flame-fringed aureole, she stands against the six-cornered (shatkona) diagram (yantra) of two superimposed triangles, also flame fringed. Curiously, however, the goddess, with her lotus base, is placed slightly off centre. ${ }^{38}$

There is no mention of the intent or purpose of her drinking the blood, rather the reader is left with exotic orientalist notions such as 'lotus', 'militant', 'red', 'naked', 'blood', 'magic', 'flame', 'goddess'. The catalogue entry goes on to emphasise the decorative elements of the thangka, and compares the illustrated thangka with similar thangkas previously exhibited-noting its rarity and potential link with a very important monastery in Tibet. Such textual processes alienate the objects from their religious and cultural associations by grounding them in an art history discourse and reducing their distinct cultural specificities into Western qualitative and quantitative measurements, which makes each piece comparable, a necessity for making judgments on value.

When museums exhibit Tibetan human bone they distance the cultural object from its cultural practices by deploying them in remote, sanitised, spotlighted museum cases, thereby effectively detaching a viewers' emotional or social response to something that, in another situation, may be abhorrent to the viewer. The human bone object is re-contextualised into the Western art history paradigm, not as once being part of a human body, but as something created from artistic resources, such as, paints, canvas, metal, and clay. ${ }^{39}$ Further, these 'made' objects are valued and hence, desired because of their uniqueness, rarity, age, workmanship and aesthetic qualities. For example, the skull-cup furnished with metal furnishings and semi precious gems, or carved with tantric figures, is more highly valued than an unadorned skull-cup. It is interesting to note, that, the unadorned skull-cup appears not to be considered exhibition worthy and, if museums have collected such pieces, they will languish in ethnographic and fine art museum basements - perhaps a silent acknowledgement that an unadorned skull is just too raw for public viewing. Further, it is rare for any 
major auction houses to offer human bone pieces. Recently, Christie's offered 'A Ritual Bone Apron'; there was no mention that the bone was human. ${ }^{40}$

Another aspect to these musings is the question of Tibetan agency. Tibet is two nations: the geographical Tibet, governed by The People's Republic of China, and the virtual Tibet, dispersed across the globe, nominally coalesced under the fourteenth Dalai Lama. Both governments believe that they have the moral right to govern Tibet. The Tibetan government in-exile is enthusiastic about promoting 'things'. It is apparent that 'Tibetan Art' is a popular vehicle by which the 'Free Tibet' message can be propagated. His Holiness has personally endorsed many 'blockbuster' exhibitions by attending openings or writing the foreward for glossy catalogues. The reality is that many people are intrigued by what they think Tibet is - a mystical isle, cut from civilisation by a sea of mountains and which was brutally awoken by the invasion of China. Truth and fiction about Tibet can be difficult to separate. Donald Lopez suggests that the promotion of Tibet in popular culture has attracted many to the cause of Tibet, but it has also imprisoned the Tibetans within a stereotyped world of exoticisms. ${ }^{41}$ The Chinese government understands the political agency of Tibetan culture and, in response to other Tibetan art blockbusters, has recently hosted an exhibition at The Bowers Museum, just outside of San Francisco. The art treasures were drawn from the ancestral home of the fourteenth Dalai Lama, the Potala. The exhibition was a huge success, even though there were continuous public demonstrations by 'Free Tibet' protesters outside the event. ${ }^{42}$

Tibetan art exhibits, whether endorsed by the current Dalai Lama or not, are very attractive exhibitions. Gold, gems and mica glitter. The grime of butter lamps and incense smoke is generally cleaned away, as is the cultural dross of temples destroyed and objects stolen. The human bone objects have been cleaned, dried and adorned. There is neither visible blood nor pungent odours. But there are art exhibitions which record or display items, which are not so kind on the senses or the emotions. I remember watching a video at the Art Gallery of New South Wales some years ago, where a young Japanese female artist lay down on a cold stone sky burial platform in a Tibetan cemetery. The butchers laid out chunks of raw meat still dripping with blood onto her naked white flesh. The vultures circled above, uneasy, sensing it was not the usual offering. Those more daring finally came down to help themselves. My mind and emotions raced and swirled. I was both fascinated and fearful for the girl - wanting to look away but I kept watching, horrified and enthralled, at the same time. Another exhibition, for which I have only seen images, has caused an outcry wherever it has gone. Gunther von Hagens' British exhibition of 'Body Worlds' displayed 25 corpses along with 175 body parts. In the exhibition, most of the body parts are exhibited in conventional fluid filled jars. However, the corpses are real bodies, which have been treated with a 'plastination' process. ${ }^{43}$ Von Hagens 
has meticulously arranged each for maximum effect. For example, a flayed male body crouches over a chessboard, while his brain can be seen through his split skull. ${ }^{44}$ Von Hagen's claim is that this type of 'Anatomy Art' will 'democratise' anatomy because it will educate the public about how their body looks on the inside. But what of the viewer? How do they feel? Did they have the same ambiguous feelings that I felt when I watched the sky burial installation? What if they were to find out that not all these bodies were willingly donated to Von Hagens' institute for plastination ${ }^{45}$ Can the contemporary Western viewer accept a 'real' person, which is now dead and skinned as an object of contemporary art? On the other hand, is the public still entranced by the Barnum-style sensationalism? Between 1997 and 2001, six million people had paid to enter the Von Hagens exhibitions; another 50000 walk through the turnstiles every week it is open.

In writing this, I am left in turmoil, frightened to feel what I feel. I ground myself in distancing myself with a pitiful cry, that I am not involved in any of this. I have not paid and would not pay to see Von Hagens' exhibition, but I am not protesting over these types of displays. I remain silent. Perhaps I am trapped by the social and political ambiguities between appearing as a 'rational being' or as an 'emotional woman' unable to detach myself from my emotions and scientifically appraise what is before me.

I conclude by asking: Is the Western attitude to the sacredness of body checked by ambivalence towards the 'us' and 'other'? What of the bodies dug up by archaeologists and property developers? What roles do time, science, art consumption or cherished memories play in negotiating the sacredness of the dead? Has the replacement of personal religious spirituality by a rational and depersonalised science constructed deep holes of irrelevance or forgetting that have no labels such as sacredness or sacrilege?

\section{ENDNOTES}

${ }^{1}$ Robert Beer (1999) has a comprehensive discussion on skull-cups in An Encyclopedia of Tibetan Symbols and Motif, Shambala, pp. 263-67.

2 For comparative Naro Dakini descriptions see Beer 1999. Beer has a comprehensive discussion on skull-cups in An Encyclopedia of Tibetan Symbols and Motif, pp. 263-7; Pal, Pratapaditya 2001, Desire and Devotion, Art from India, Nepal and Tibet: In the John and Berthe Ford Collection, Philip Wilson Publishers, London, pp. 274-5; Rhie, Marilyn M. and Robert A. F. Thurman, 1991, Wisdom and Compassion, Thames \& Hudson, p. 299; Mullin, Glen H. 2003, Female Buddhas: Women of Enlightenment in Tibetan Mystical Art, Clear Light Publishers, Santa Fe, pp. 154-5; Sotheby's, Indian and Southeast Asian Art, Wednesday September 24, pp. 58-9.

3 Tibetan Buddhism is also known as Vajrayana (Diamond Vehicle) Buddhism, Tantric Buddhism, Tantrayana or Esoteric Buddhism. It is a subset of Mahayana Buddhism, which itself broke away from the Theravada Buddhism in c. 200 A.D. Each form of Buddhism maintains the core beliefs of Sakyamuni Buddha, however, they follow varying practices in an effort to break from the ever-circling wheel of rebirth.

4 The obstacles of samsara are greed, lust and ignorance.

5 Beer provides a comprehensive list for the skull-cups in An Encyclopedia of Tibetan Symbols and Motif, pp. 263-4. 
${ }^{6}$ Polo, Marco 1982 [1958], The Travels, Penguin, Hammondsworth, p. 110. It is interesting to note that Marco Polo (c. 1254-1324) mentions how in the Great Khan's court the Tibetan Buddhists had a peculiar custom, 'When a man is condemned to die and is put to death by the authorities, they take his body and cook and eat it. But, if anyone dies a natural death, they would never think of eating him'. Perhaps this is an early account of the desirability of particularly potent ritual objects.

7 Beer, 1999, p. 266; illustration 265.

8 Dowman, Keith 1997, The Sacred Life of Tibet, Thorsons, London, p. 234. See also Wylie, Turrell $1964-$ 65, 'Mortuary Customs at Sa-Skya, Tibet', Harvard Journal of Asiatic Studies, vol. 25, pp. 229-42.

9 The Zoroastrians of Persia practiced intact body sky burial, this tradition is carried on by the Parsi of India. Seshadri, Sudha September 2004, 'Buried in the Sky: Some Parsi Zoroastrians Are Having a Hard Time Accepting Changes to Traditional Death Rituals', Science \& Theology News, <http://www. beliefnet.com/story/152/story_15243.html>, viewed 28 September 2005.

${ }^{10}$ Wylie, 1964-65, p. 232; Ekvall, Robert B. 1964, Religious Observances in Tibet: Patterns and Function, University of Chicago Press, Chicago, p. 234.

11 Although Wylie argues that there is no clear evidence to support this claim, 1964-65, p. 232.

12 Ekvall, 1964, p. 72-7.

13 The journey through the Bardo is mapped in the Tibetan Book of the Dead. The version by Rinpoche 1987 has become the most popular.

14 Tsampa is a Tibetan staple. It is made from pounded barley flour formed into small balls, which is usually served mixed in with tea and yak butter.

15 Dowman, 1997, p. 234.

16 Wylie, 1964-65, p. 239.

17 I acknowledge that there were Protestant groups such as those mentioned in Ian Hunter's chapter in this volume, which were opposed to the idolisation of anything outside that of the Christian word and good deeds.

18 Bentley, James 1985, Restless Bones: The Story of Relics, Constable \& Co. Ltd., London, p. 37.

19 Bentley, 1985, p. 183.

20 Brown, Peter L. R. 1977, Relics and Social Status in the Age of Gregory of Tours, Berkshire, University of Reading, p. 4.

21 St Thomas à Becket's bones attracted not just English attention. For example, in 1179, King Louis VII of France gave to Canterbury Cathedral 'a cup of pure gold, a huge ruby known as the Régale of France, and an annual allowance of about 1600 gallons of wine'. Butler, John 1995, The Quest for Becket's Bones: The Mystery of the Relics of St Thomas Becket of Canterbury, Yale University Press, New Haven, p. 20. See also Bentley for an account of the profit made from ordinary pilgrims visiting Canterbury Cathedral, 1985,pp. 108-12.

22 Bentley, 1985, pp. 108-12.

23 Hermann-Mansard, cited in Bentley, 1985, p. 29.

24 Geary, Patrick 1978, Furta Sacra: Thefts of Relics in the Central Middle Ages, Princeton University Press, Princeton, pp. 70-1.

25 Anon., 1900, 'History of Modern Anatomy', <http://www.fact-index.com/h/hi/history_of_modern_anatomy.html>, viewed 28 September 2005.

26 The Anatomy Act of 1832 provided anatomists with bodies from execution, and bodies which were not claimed within 48 hours of death, unless they had left behind a request in writing for their body not to be dissected. As workhouses reduced in number, the Inspector of Anatomy in 1920 ruled that unclaimed bodies from asylums could be used. The increasing secularisation of Western society since WWI has witnessed an increasing number of bodies being left to science, so much so, that almost all bodies dissected today for medical purposes in Great Britain have been donated. Channel 4, 'The Anatomists: The Anatomy Act', <http://www.channel4.com/science/microsites/A/anatomists/ethicsl.html\#act>, viewed 28 September 2005.

27 Contemporary funereal practices can send a dearly departed into space, have a star named after them and have their ashes built into an artificial reef. See websites such as Space services inc. \& eternal reefs. 28 Neely, Paula Kripaitis 2001, '17th Century Jamestown Burials: Tell Tales of Stressful Beginnings', Press Release, <http://www.apva.org/apva/burial.pdf>, viewed 28 September 2005.

29 By the twentieth century, the expanded middle class could prove their economic and social status by acquiescing to restrictive mourning customs, which not only prescribed specific clothing, jewelry 
and hats but also restricted the bereaving family members from economic activities and social contact for up to two and a half years. Vanessa Harding in Channel 4, 'An Interview with Vanessa Harding', The Great Plague; Channel 4 history programme transcript, <http://www.channel4.com/history/microsites/H/history/e-h/harding.html>, viewed 28 September 2005.

30 Llewellyn, Nigel 1991, The Art of Death: Visual Culture in the English Death Ritual c.1500-c.1800, Reakton in association with Victoria \& Albert Museum, London, pp. 60, 85.

31 Interestingly, I watched the exhibit space throughout the day and few conference attendees went near it, hence I was aware that the exhibit was possibly having an impact. After the conference closed a small number of attendees did speak off the record, noting their discomfort at sharing the room with human bone objects.

32 Many British missionaries and East India Company personnel wrote about the 'Devil Dances' in Hemis, Ladakh, historically referred to as 'Little Tibet'. See Coombe, G. 1975, [1926] A Tibetan on Tibet: being the travels and observations of Mr Paul Sherap (Dorje Zödba) of Tachienlu; with an introductory chapter on Buddhism and a concluding chapter on the Devil Dance Kathmandu, Ratna Pustak Bhandar, pp. 179-200; Anon. 1926, 'The Realm of the Devil Dancers', New York Times, 25 July.

33 Kircher, Athanasius (ed.), 1677, China Illustrata, apud Jacobum á Meurs, Amstelodami, p. 109. Greuber's letters were edited by Kircher.

34 Polo, The Travels, p. 110.

35 Anon., 'Made from Human Bones', New York Times, 19 April 1930, p. 25.

36 Mandeville, 1964, pp. 203-4.

37 Note all three exhibitions traveled to one or more venues within the United States. One was 'Himalayas: An Aesthetic Adventure', (The Art Institute of Chicago, 5 April to August 17, 2003). The agenda of Himalayaswas aesthetic representation only. Pal, 2001. Another was 'Circle of Bliss' (Los Angeles County Museum 5 October 2003 to 4 January 2004). The agenda was the re-introduction of Tibetan and Nepalese devotional/meditational knowledge back into objects selected for their aesthetic values. Huntington, John and Dina Bangdel, 2003, Circle of Bliss, Serindia Publications, Chicago. In 'Tibet: Treasures from the Roof of the World'(The Bowers Museum, 12 October 122003 to 12 September 2004), the agenda here was art aesthetics but it was also caught in a controversial political framework. The People's Republic of China authorised the exhibition of Tibetan treasures from the Potala Palace and in doing so claimed sole ownership and access to objects that were the current self-exiled Dalai Lama's birthright. Byrd, Vickie C., Nancy R. Johnson, and Kathie A. Hamilton, 2003, Tibet: Treasures from the Roof of the World, Bowers Museum of Cultural Art.

38 Pal, 2001, pp. 274-5.

39 In some cases, the exhibition caption accompanying the exhibit may just state 'bone' and only the reading of the catalogue explains the type of bone-human. For example, see 'Ritual Apron' in Hall, Dawn (ed.) 1997, Tibet: Tradition \& Change, The Albuquerque Museum, Albuquerque, pp. 170-1.

40 Christies, Indian and Southeast Asian Art, 25 March 2004, p. 98.

41 Lopez, Donald Jr. 1998, Prisoners of Shangri-La: Tibetan Buddhism and the West, University of Chicago Press, Chicago.

42 Amateau, Albert 'Chinese takeover of Tibet protested at art opening', The Village, 3 March 2005, $<$ http://www.tibet.ca>, viewed World Tibet News (WTN) 18 September 2005. Although this article, published in The Village, was written when the Bowers Museum exhibition arrived at the Rubin Museum of Art in New York City, it does present a good summary of the arguments used by both the protester and the collector.

43 Stuart Jefferies, 'The naked and the dead', The Guardian, 19 March 2002, < http://education.guardian.co.uk/higher/arts/story/0,,670045,00.html>, viewed 28 September 2002. 'Plastination' is a process developed by Von Hagens by which the body is preserved by replacing water in the cells with plastic materials. It takes about 1500 hours work and costs up to A\$50 000. The result is an odourless and durable realistic-looking corpse.

44 I could not include in the body of the text the fact that Von Hagens also included in his British exhibition a bisected cadaver of an eight-months pregnant woman with her womb opened to reveal the foetus. O'Rorke, Imogen 'Skinless wonders...', The Observer, 20 May 2001, <http://observer.guardian.co.uk/review/story/0,,493200,00.html> viewed 28 September 2005; Jefferies, 'The naked and the dead'.

45 O'Rorke, 'Skinless wonders...'. Because of Cyrillic characters identified on a flayed skin in the Berlin exhibition, it was discovered that 56 Siberian peasants and mental patients from Novosibirsk were in Von Hagens institute collection; they had not been donated. 